\title{
FLEXIBILIZAÇÃO DOS VÍNCULOS DE TRABALHO NA ATENÇÃO SECUNDÁRIA: LIMITES DA POLÍTICA NACIONAL DE SAÚDE BUCAL
}

\author{
FLEXIBLE WORKING TIES IN SECONDARY CARE: LIMITS OF THE NATIONAL ORAL HEALTH POLICY \\ FLEXIBILIZACIÓN DE LOS VÍNCULOS DE TRABAJO EN LA ATENCIÓN SECUNDARIA: LÍMITES DE LA \\ POLÍTICA NACIONAL DE SALUD BUCAL
}

\author{
Raquel Santos de Oliveira ${ }^{1}$ \\ Heloisa Maria Mendonça de Morais ${ }^{2}$
}

Resumo $\mathrm{O}$ artigo explora as mudanças que vêm ocorrendo na organização do trabalho no âmbito da Política Nacional de Saúde Bucal, considerando as transformações ocorridas na esfera do trabalho no cenário global da reestruturação produtiva. Esse fenômeno, inicialmente observado na organização do trabalho industrial, vem sendo descrito também no setor de serviços, sendo visíveis alguns de seus efeitos no campo da saúde. No Brasil, desde a Reforma do Estado de 1995, foram implantadas modalidades contratuais flexíveis, o que possibilitou a instituição legal de vínculos precários na rede de serviços de saúde pública e privada. O presente estudo é descritivo com componentes próprios das abordagens quantitativa e qualitativa. O estudo de campo foi realizado nos 13 Centros de Especialidades Odontológicas da Região Metropolitana do Recife, Brasil, 2010 e objetivou investigar o fenômeno da precarização e suas manifestações na atenção à saúde bucal. O material estudado evidenciou um contexto de precarização do trabalho nos serviços investigados, com repercussões sobre a qualidade do atendimento prestado à população usuária dos centros, condição essa que constitui um dos desafios a ser enfrentado pela Política Nacional de Saúde Bucal.

Palavras-chave trabalho; precarização; mercado de trabalho; saúde bucal.
Abstract The article addresses the changes taking place in work organization under the Brazilian Oral Health Policy, considering the changes occurring in the organization of labor in the global scenario of productive restructuring. This phenomenon, first observed in the organization of industrial work, has been described also in the service sector, being visible some of its effects in the health field. In Brazil, since the 1995 State Reform, flexible contractual models were implemented, which allowed the legal institution of precarious labor ties in the public and private healthcare services. This study is descriptive, with its own components of quantitative and qualitative approaches. The field study was conducted in 13 Specialized Dental Clinics (SDCs) of the Metropolitan Region of Recife and aimed to investigate the phenomenon of precariousness and its manifestations in oral health care. The material studied evidenced a precarious context of work in investigation services, with repercussions on the quality of care provided to the population user of the centers, a condition that consists one of the challenges to be faced by the National Oral Health Policy.

Keywords job; precariousness; job market; oral health. 


\section{Introdução}

Desde a década de 1970 e em escala mundial, vem ocorrendo um processo de mudanças na totalidade do complexo social, afetando centralmente o mundo do trabalho. À luz dessas transformações, este artigo objetiva analisar o fenômeno da precarização do trabalho, centrando o enfoque na atenção à saúde, no caso particular da saúde bucal.

No cenário das mudanças decorrentes da reestruturação produtiva, cujas bases estão alicerçadas em políticas macroeconômicas de cunho neoliberal, uma das drásticas consequências foi o esfacelamento das relações de trabalho as quais, mediadas pela estratégia da flexibilização, passam a se expressar por novas formas de contratos temporários, terceirizados, sem proteção social.

O fenômeno da precarização do trabalho, questão de análise desta investigação, tem sido conceituado e apreendido de óticas distintas que transitam desde a esfera do direito administrativo até o âmbito da economia e da política. Relações de trabalho precárias, tanto no setor público quanto no privado, são caracterizadas: pelas modalidades contratuais que possuem déficit ou ausência total de direitos ou de proteção social trabalhista e previdenciária (Girardi, 1996; Nogueira, Baraldi e Rodrigues, 2004; Baraldi, Díaz e Martins, 2009; Girardi et al., 2010); pela condição de instabilidade dos vínculos laborais - o que gera insegurança para o trabalhador, estatal ou não (Druck e Thébaud-Mony, 2007; Alves, 2009; Antunes, 2009; Hirata, 2009; Girardi et al., 2010) e por baixos salários (Organización Internacional del Trabajo, 1999; Antunes, 2008; Braga, 2012).

Isso posto, cabe demarcar que a perspectiva que orienta o presente estudo é ampla, portanto compreende um conjunto de situações relativas aos vínculos laborais que imprimem aos mesmos a condição de insegurança, de desproteção social e de baixos salários. Ou seja, afastar-se-ia da linha de pensamento segundo a qual os limites da precariedade são impostos pelo marco legal-formal prevalecente para atender à realidade objetiva decorrente da reconfiguração do Estado tal como definida desde os anos 1990.

Autores vinculados à corrente de pensamento crítica, norteadores desta investigação, como Mészáros (2002), Antunes (2008), Druck e Thébaud-Mony (2007) e Boltanski e Chiapelo (2009), argumentam que a característica dominante das transformações sociais desde as duas últimas décadas do século XX foi a erosão do trabalho regulamentado e estável, advinda do processo de flexibilização da legislação social do trabalho.

Para Bourdieu (1998, p. 123), a flexibilidade é uma estratégia de precarização, inspirada em razões econômicas e políticas, fruto de uma 'vontade política' e não de uma 'fatalidade econômica', supostamente dada pela mundialização. 
Kalleberg (2009) argumenta que o trabalho precário tem consequências de longo alcance, atravessando muitas áreas que preocupam cientistas sociais, bem como os trabalhadores e suas famílias. Gera insegurança para muitos e afeta amplamente não só a natureza do trabalho, os locais de trabalho e a experiência dos trabalhadores, mas também vários aspectos da vida individual e social não necessariamente relacionados ao trabalho.

No Brasil, a precarização resultou das reformas liberais iniciadas nos anos 1990 que levaram à privatização e à desregulamentação do trabalho, contribuindo para um acentuado desemprego e a ampliação dos níveis de informalidade, até mesmo no setor público. Um conjunto de instrumentos legais foi aprovado e introduzido na administração pública, objetivando justificar a flexibilização dos vínculos empregatícios. Como consequência dessas determinações macroestruturais, também aqui a força de trabalho passou a vivenciar não apenas um processo de desconstrução dos direitos trabalhistas e previdenciários, mas também a insegurança quanto à estabilidade no trabalho.

O setor saúde não ficou à margem dessas transformações. Pesquisas de alcance nacional encomendadas pelo Ministério da Saúde realizadas no início dos anos 2000 dimensionaram esse fenômeno no âmbito da atenção básica do Sistema Único de Saúde (SUS). Naquele momento, verificava-se que dois terços dos municípios pesquisados vinculavam os profissionais ao Programa Saúde da Família (PSF) por meio de contratos precários (contratos temporários irregulares e contratos com autônomos prestadores de serviços) ou terceirizados (Brasil, 2002 e 2004b).

Também no caso da atenção odontológica, antes mesmo da criação da Política Nacional de Saúde Bucal (PNSB) em 2004, já se verificavam profissionais trabalhando em regimes precários (Nogueira, 1999; Moimaz, 2003; Nogueira, Baraldi e Rodrigues, 2004). Sabe-se, contudo, que foi apenas no ano 2000, quando o Ministério da Saúde propôs mudanças na atenção à saúde bucal para assegurar o cumprimento dos princípios do SUS, que a assistência odontológica foi definitivamente incorporada aos serviços básicos de saúde. Desde março de 2004, o Ministério da Saúde vem implantando a PNSB, também denominada "Brasil Sorridente", com o objetivo de ampliar o atendimento e melhorar as condições de saúde bucal da população. Essa política incentiva o aumento da oferta de procedimentos nos níveis secundário da atenção pela implantação dos Centros de Especialidades Odontológicas (CEOs) (Brasil, 2004a).

Desse modo, fica claro que desde a PNSB, bem como de medidas que a antecederam, colocava-se um cenário no qual estavam postas as condições macroestruturais que resultariam no processo de flexibilização e de precarização do trabalho (Mészáros, 2002; Druck e Thébaud-Mony, 2007; Antunes, 2008). Pode-se afirmar, portanto, que a política de saúde bucal 
nasceu no contexto do trabalho precário, subcontratado, sem proteção social.

Assim, em 2006, na pesquisa realizada pelo Observatório de Recursos Humanos do Núcleo de Estudos em Saúde Coletiva da Universidade Federal do Rio Grande do Norte (Nesc/UFRN) juntamente com o Ministério da Saúde (Brasil, 2006a), os dados demonstravam que, em relação aos cirurgiões-dentistas, quase a metade deles $(47,16 \%)$ era contratada por vínculos precários, somando-se os contratos temporários e os comissionados com aqueles denominados sem contratos.

Lourenço et al. (2009) também apontavam para a existência da precarização das relações de trabalho nas Equipes de Saúde Bucal (ESBs) em 310 municípios do estado de Minas Gerais, ao demonstrarem que, quanto à forma de contratação dos cirurgiões-dentistas, $21 \%$ das ESBs referiram teste seletivo interno; $12 \%$, concurso externo; $16,3 \%$, credenciamento; e 50,6\% relataram outras formas de contratação, tais como indicação política, nomeação, licitação, terceirização, contratos por cooperativas, contrato temporário, contrato de prestação de serviços.

O pressuposto desta investigação é que o fenômeno da precarização, ao penetrar na organização do trabalho, termina por interferir na intencionalidade anunciada da PNSB. Isso porque a oferta inadequada das condições de trabalho que se consubstanciaria na instabilidade dos vínculos, na falta de garantia dos direitos sociais e em salários incompatíveis com a qualificação profissional, em vez de atrair os profissionais para o exercício responsável, tem resultado em sua desresponsabilização ante os objetivos dessa política.

$\mathrm{Na}$ área da saúde, a odontologia incluída, são poucas ainda as pesquisas que abordam a precarização do trabalho. Além do mais, para além dos discursos que atribuem os problemas que atingem a força de trabalho a determinações intrínsecas ao setor saúde, é possível atestar a falta de abordagens totalizantes para o problema da precarização. Desse modo, esta pesquisa, ao investigar as relações de trabalho dos cirurgiões-dentistas que trabalham no CEO, pôs em evidência o fenômeno da precarização, com o intuito de se opor ao vazio acima referido.

\section{As transformações na esfera do trabalho no âmbito da saúde no cenário da reestruturação produtiva}

A reestruturação produtiva tem sido abordada como a grande transformação ocorrida nas sociedades capitalistas no final do século XX, com consequências radicais para a esfera do trabalho. Ao objetivar a recuperação do ciclo reprodutivo dos capitais, não alterou, contudo, os pilares do modo de produção capitalista, mantendo essencialmente intocada a subsunção do 
trabalho ao capital. “A condição crucial para a existência e o funcionamento do capital é que ele seja capaz de exercer comando sobre o trabalho" (Mészáros, 2002, p. 710).

Como resposta à crise dos anos 1970, das quais o neoliberalismo e a reestruturação produtiva são expressão, intensificaram-se as transformações do processo produtivo, por meio do avanço tecnológico, da constituição das formas de acumulação flexível e das alternativas aos modos de produção fordista/taylorista, com destaque para o surgimento do toyotismo.

No bojo dessas transformações, destacam-se, entre outras consequências, o aumento significativo da parcela da população que não possui perspectivas de emprego estável; a perda de direitos sociais; o rebaixamento salarial; e a intensificação da extração de trabalho de modo ampliado.

É possível afirmar que as noções que demarcam a flexibilização são a informalização do trabalho, a fragmentação dos trabalhadores, a individualização, a fragilização dos coletivos e a crise dos sindicatos, além da degradação das condições de saúde e de trabalho, todas essas condições agravadas pela perda de 'direitos de todos os tipos' (Mészarós, 2002; Antunes, 2007).

Boltanski e Chiapello (2009) interpretam que a flexibilidade possibilitou transferir o peso das incertezas do mercado para os assalariados e também para os subcontratados e outros prestadores de serviços. Segundo os autores, essa prática, que consiste em ocupar empregos fixos recorrendo apenas a um número "mínimo possível" de pessoas e utilizar "trabalho externo" como complemento, tem resultado paralelamente no desenvolvimento da terceirização e do trabalho temporário.

Para Druck e Thébaud-Mony (2007), a flexibilização é um processo que tem condicionantes macroeconômicos e sociais derivados de uma nova fase de mundialização do sistema capitalista, hegemonizado pela esfera financeira, cujas fluidez e volatilidade, típica dos mercados, contaminam não só a economia, mas a sociedade em seu conjunto, e, dessa forma, generalizam a flexibilização para todos os espaços, especialmente para a esfera do trabalho. Nessa fase, a liberalização do mercado atinge níveis inéditos de desenvolvimento.

No Brasil, desde os anos 1990, as políticas de governo assumiram os pressupostos neoliberais, alicerçados no processo de desregulamentação dos mercados de capitais e do trabalho; e no controle do déficit fiscal com cortes financeiros nas políticas sociais e pela desmontagem do setor produtivo estatal. Na sequência, a proteção social também foi flexibilizada pelas perdas decorrentes das reformas da legislação trabalhista e previdenciária.

O setor saúde tem sido particularmente afetado pelas possibilidades abertas com a Reforma do Estado de 1995, materializada pelo Plano Diretor da Reforma do Estado no governo de Fernando Henrique Cardoso (FHC). Tal 
proposição teve como objetivos centrais o ajuste fiscal, a privatização dos bens e serviços públicos e a liberalização comercial. Entre outras consequências advindas dessa reforma, destacam-se a transferência do fundo público para o setor privado, a terceirização dos serviços públicos e a flexibilização dos contratos de trabalho.

Granemann (2008) avalia que uma reforma do Estado tanto pode operar na direção de aumentar os direitos da força de trabalho quanto aprofundar as exigências de acumulação do capital. No caso do Brasil, sem dúvida a natureza da reforma tem a segunda perspectiva, ou seja, vêm afetando particularmente os interesses e direitos da força de trabalho. A autora argumenta ainda: "quando o capital imprime sua lógica para a totalidade da vida social também o Estado tem de ser contrarreformado para que as instituições e as políticas sociais que garantem os direitos dos trabalhadores se transmutem em negócios que promoverão lucratividade para o capital" (2008, p. 50).

Na mesma direção, Behring (2008) explica que o projeto de contrarreforma do Estado iniciado na década de 1990 implicou um profundo retrocesso social em benefício de poucos. Significou o abandono das possibilidades de ruptura com a heteronomia e de uma redemocratização política e econômica inclusiva dos trabalhadores e da maioria da população brasileira.

Em 2004, o Ministério da Saúde, em documento intitulado “Gestão do trabalho e da regulação profissional em saúde", avaliava que, no cenário das reformas estruturais do Estado, presenciou-se o surgimento de ideias contrárias ao processo de vinculação dos servidores pelo regime estatutário. A promulgação da emenda constitucional n 19/1998 deu nova redação ao artigo 37 da Carta Magna, flexibilizando a forma de vínculo de trabalho na administração pública. Essa política, preconizada pelo governo federal e seguida por boa parte dos estados e municípios, acabou provocando um processo de precarização do trabalho no SUS e a consequente redução de postos de trabalho na administração pública. Em decorrência, no ano de 2002, cerca de 600 mil trabalhadores do SUS estavam precarizados, o equivalente a $30 \%$ da força de trabalho em saúde (Brasil, 2004b).

As mudanças introduzidas por essa emenda incidiram centralmente sobre duas questões relacionadas ao trabalho no serviço público: a estabilidade e a aposentadoria integral. A partir de então, ficou legalmente instituída a adoção do regime da Consolidação das Leis do Trabalho (CLT) na administração pública, ou seja, o emprego público, que difere do Regime Jurídico da União (RJU) nas seguintes características: ausência de estabilidade, processo seletivo diferenciado, remuneração diferenciada e não existência de carreira, além de a previdência passar a ser regida pelo Regime Geral da Previdência (March, 2011).

A respeito da problematização da natureza dos vínculos empregatícios no âmbito do SUS, dados de um estudo realizado em 41 municípios com 
mais de 100 mil habitantes em sete estados das regiões Sul e Nordeste, que entrevistou 4.749 trabalhadores de saúde, revelaram que menos da metade $(40 \%)$ dos trabalhadores ingressaram por concurso público e $30 \%$ dos trabalhadores da Região Sul não possuíam os direitos trabalhistas. Esse percentual alcançava $42 \%$ na Região Nordeste (Tomasi et al., 2008).

Em estudo mais recente, Girardi et al. (2010) constataram a existência de trabalho precário nas Estratégia Saúde da Família (ESF). Os dados são significativos: em 2009, nos municípios pesquisados pelos autores, 76,3\% dos médicos, $57,7 \%$ dos enfermeiros e 55,9\% dos dentistas encontravam-se no regime de trabalho desprotegido (vínculos temporários, prestação de serviços e demais vínculos sem proteção ou não plenamente protegidos pelos direitos trabalhistas).

Ainda sobre as relações laborais vigentes na atenção básica, outro estudo constatou que $38 \%$ dos trabalhadores das regiões Sul e Nordeste possuíam vínculos precários (Silveira et al., 2010). Mendonça et al. (2010), em artigo recente a respeito da gestão do trabalho na ESF, registraram que aproximadamente $80 \%$ dos médicos e enfermeiros possuíam vínculos estatutários. Em seus resultados, destacaram a importância do vínculo trabalhista estável para a fixação dos profissionais na ESF, bem como para a melhoria do desempenho das ações de saúde.

Outros autores mencionam que os efeitos da flexibilização sobre a força de trabalho em saúde tem sido causa de insatisfação e diminuição com o compromisso público, de baixa estima, de fragmentação do trabalho e de descontinuidade na prestação de ações de saúde (Cordeiro, 2001). Em relação à PNSB, especial atenção viria sendo dedicada à inserção e à expansão das Equipes de Saúde Bucal no PSF. Assim, a odontologia foi uma das áreas da saúde que mais expandiu sua força de trabalho no Brasil nos últimos anos, tornando-se a terceira categoria de nível superior da equipe de saúde, com 57 mil postos de trabalho, depois da medicina e da enfermagem (Brasil, 2004b).

No que se refere às pesquisas no setor público odontológico, os dados do estudo sobre "Recursos humanos nos serviços públicos municipais de saúde bucal no Brasil" (Brasil, 2006b) apontam que, em relação ao tipo de contrato, apenas $38,2 \%$ dos dentistas eram concursados. O vínculo de estatutário predominava nos municípios com mais de 500 mil habitantes, os quais equivalem a $80 \%$ dos municípios pesquisados. Já nos municípios com até 50 mil habitantes, em $45 \%$ predominava o vínculo de prestador de serviços/autônomo. As regiões Nordeste e Centro-Oeste possuem o menor número de municípios com cirurgiões-dentistas concursados no PSF.

Então, procede que o preceito neoliberal de flexibilização, adotado primeiramente pelo governo federal e, posteriormente, pelos governos estaduais e municipais, ao mesmo tempo em que vem possibilitando às três es- 
feras do governo maior liberdade para contratação, remuneração e expansão da força de trabalho em saúde, tem feito isso pela predominância de relações instáveis, ou seja, promotoras de insegurança. Para Hirata (2009), estaríamos vivendo hoje em dia um status de legitimação social e científica da precariedade, avaliada de forma positiva e, em outras situações, apresentada como inelutável, fatal, quase natural.

\section{Metodologia}

O presente estudo ${ }^{3}$ é descritivo e exploratório, com componentes próprios das abordagens quantitativa e qualitativa. O estudo de campo foi realizado nos 13 CEOs localizados nos municípios da Região Metropolitana da cidade do Recife, no período de 7 de junho a 12 de agosto de 2010. A escolha dos CEOs se justifica pela importância estratégica desses serviços para a garantia da integralidade da atenção, conforme a PNSB do Ministério da Saúde.

O material empírico foi obtido por meio de entrevistas semiestruturadas, resguardando-se um espaço para o relato livre dos informantes. As entrevistas foram realizadas com 13 cirurgiões-dentistas, identificados de A a $\mathrm{M}$, sendo um profissional de cada CEO. O critério de inclusão dos indivíduos para participar da pesquisa foi o tempo de trabalho, sendo selecionados em cada serviço o cirurgião-dentista com mais tempo de exercício profissional, com a intencionalidade de se perscrutarem as mudanças ocorridas em seus cotidianos de trabalho no contexto de precarização do trabalho.

Para a análise da natureza contratual de trabalho, foi pesquisado o universo total dos cirurgiões-dentistas alocados nos 13 CEOs investigados, constituindo uma amostra de 118 profissionais. Essa informação foi fornecida pelos coordenadores de Saúde Bucal dos municípios investigados. O material obtido foi analisado à luz da categoria analítica selecionada - precarização do trabalho - e das categorias empíricas (agora já desagregadas em seus elementos constitutivos) correspondentes: formas de contratação e seleção, usufruto de direitos trabalhistas, jornada de trabalho e a existência, ou não, de plano de cargo, carreira e salário.

Convém reafirmar que o fenômeno da precarização do trabalho aparece na literatura sob ângulos interpretativos diferenciados. Ora a precarização aparece como um efeito - irrefutável - do fenômeno da 'flexibilização' no cenário da crise contemporânea do capitalismo, ora enquanto uma 'decorrência natural' das mudanças legais e formais ocorridas na administração pública. Como se pode depreender do embasamento teórico-conceitual adotado, os autores deste estudo estão orientados pela primeira perspectiva, por entenderem que a flexibilização das relações de trabalho tem um efeito destrutivo sobre o anti- 
go regime de relações laborais vigente no Brasil anteriormente a 1998, quando foi promulgada a emenda constitucional $\mathrm{n}^{\circ} 19$.

Como a presente pesquisa se detém sobre as relações de trabalho no âmbito da esfera pública, as formas legais de vínculos previstas na administração pública foram revisitadas para esclarecer o debate. Sabe-se que o texto constitucional disponibiliza várias formas de ingresso no cargo ou emprego público, sendo a aprovação em concurso público de provas ou de provas e títulos, como regra geral, estabelecida pelo artigo 37, inciso II. Contudo, a emenda constitucional $n^{\circ} 19$, ao modificá-lo, passou a permitir a nomeação sem concurso público para os cargos em comissão (aqueles de livre nomeação e livre exoneração). Desse modo, o inciso IX do referido artigo 37 prevê, desde então, a contratação por tempo determinado no caso de necessidade temporária de excepcional interesse público. O posicionamento dominante na doutrina e na jurisprudência indica que a situação de excepcional interesse público deve estar estabelecida em lei específica, ou seja, o ente federativo, mediante lei própria, estabelecerá o que é a situação de excepcionalidade (Ribeiro, 2006).

Tendo em vista os resultados que serão apresentados a seguir, é importante ainda ressaltar que a forma predominante de trabalho irregular no setor público é aquela que decorre da contratação sem obediência ao requisito constitucional de concurso ou seleção pública, qualquer que seja a modalidade de remuneração adotada pelo gestor, usando os recursos públicos de que dispõe (Nogueira, Baraldi e Rodrigues, 2004).

Quanto às considerações éticas da pesquisa, todos os indivíduos pesquisados foram indagados se gostariam de participar do estudo. Em caso positivo, assinaram um termo de consentimento livre e esclarecido que seguiu as normas da resolução no 196/1996 do Conselho Nacional de Saúde, permitindo sua inclusão no estudo. Esta pesquisa foi submetida à análise do Comitê de Ética em Pesquisa (CEP) da Universidade Federal de Pernambuco (UFPE), com o parecer de aprovação sob o número do registro CEP/CCS/UFPE $n^{\circ}$ 088/2010 e CAEE $n^{\circ}$ 0085.0.172.000-10.

\section{Resultados e discussão}

Como já anunciado, o cenário das contratações flexíveis, ou seja, precárias, está presente na organização do trabalho no setor público odontológico, convergindo com a hipótese da presente pesquisa. $\mathrm{Na}$ sequência, serão apresentados os resultados relativos às formas de contratação e seleção, ao usufruto de direitos trabalhistas, bem como à jornada de trabalho e à existência, ou não, de plano de cargo, carreira e salário. 
No que diz respeito à forma de contratação, 8 dos 13 profissionais entrevistados afirmaram que seus contratos de trabalho com os municípios eram temporários. Quanto ao universo dos 118 cirurgiões-dentistas, mais da metade $(56 \%)$ possuíam esse mesmo tipo de contrato. Trata-se, portanto, de vínculos laborais instáveis, caracterizando trabalho precário, sob a roupagem das novas modalidades de ingresso no serviço público asseguradas pela emenda constitucional $n^{\circ} 19$. É sabido que o contrato por tempo determinado é fonte promotora de insegurança e instabilidade para a força de trabalho (Girardi, 1996; Hirata, 2009). Em muitas situações, esse tipo de contrato não assegura direitos trabalhistas, e mesmo quando assegura, é de modo temporário.

Os autores que fundamentam este estudo (Mészáros, 2002; Druck e Thébaud-Mony, 2007; Antunes, 2008; Boltanski e Chiapello, 2009) interpretam que o trabalho por tempo determinado é, sim, trabalho precário. E para tanto, diferentemente do que entende a atual administração pública brasileira, tomam em conta o caráter da temporalidade, assumindo-o como parte da imanência do conceito de precarização.

Desse modo, fica demonstrado que o recurso dos contratos temporários não constitui uma prática dirigida precisamente a solucionar 'situações excepcionais de interesse público', mas vem se configurando como 'uma brecha' normativa introduzida nos dispositivos da administração pública para assegurar um caráter de legalidade a contratos de trabalho flexíveis.

Em oposição a essa perspectiva, Nogueira, Baraldi e Rodrigues entendem que o contrato temporário, além de lícito do ponto de vista do direito administrativo, "será sempre um contrato que resguardará direitos trabalhistas e sociais, ainda que o trabalho se exerça por tempo determinado e seja de excepcional interesse público" (2004, p. 26).

Sobre essa específica interpretação, faz-se necessário apresentar algumas considerações. Em primeiro lugar, o fato de o contrato temporário se encontrar legalmente amparado não significa necessariamente que todos os trabalhadores contratados sob essa condição estejam socialmente protegidos. Ou seja, nem todos os contratos de trabalhos temporários são regidos pela CLT. Nesta investigação, no universo dos 118 profissionais, já incluídos os estatutários, $84,6 \%$ afirmaram possuir direitos trabalhistas, enquanto $15,4 \%$ não possuíam direitos trabalhistas ou previdenciários. Ademais, obtiveram-se evidências de que entre aqueles que afirmavam possuí-los, podia não se tratar do gozo pleno desses direitos, tal como assegurado pela CLT, mas de um usufruto fragmentado, vez que o escopo de proteção social oferecido variava entre os municípios pesquisados.

Em segundo lugar, acrescenta-se ainda o fato de que trabalhadores com vínculos por tempo determinado, a depender de circunstâncias políticoeconômicas, poderão vir a constituir proximamente o exército dos desem- 
pregados. Isso porque insegurança e instabilidade são partes constitutivas desse tipo de vínculo laboral.

Quanto à forma de seleção para a admissão no emprego, a pesquisa demonstrou que quase dois terços dos 13 entrevistados foram admitidos de forma irregular na administração pública, porque selecionados apenas pela análise de currículo ou entrevista, ou até mesmo por quaisquer outras indicações. Tanto que os autores acima mencionados referem tratar-se de uma contrariedade ao que dispõe o inciso II do artigo $37^{\circ}$ :

a investidura em cargo ou emprego público depende de aprovação prévia em seleção pública ou concurso público de provas ou de provas e títulos, de acordo com a natureza e a complexidade do cargo ou emprego, na forma prevista em lei, ressalvadas as nomeações para cargo em comissão declarado em lei de livre nomeação e exoneração (Nogueira, Baraldi e Rodrigues, 2004, p. 69).

Quanto aos baixos salários, eles também compõem o fenômeno da precarização. Desse modo, chama atenção que a média salarial de dois terços dos entrevistados tenha se situado entre $\mathrm{R} \$ 1.000,00$ a $\mathrm{R} \$ 1.999,00$ por vinte horas semanais de trabalho. Esses valores, além de variarem entre os municípios pesquisados, foram relatados pelos entrevistados como muito baixos tendo em vista suas qualificações profissionais, considerando que majoritariamente eram especialistas. Seria o caso de indagar como se daria a adesão desses profissionais às perspectivas doutrinárias da PNSB tendo em vista níveis salariais tão insatisfatórios.

Essa problemática também foi destacada no estudo realizado por Moimaz, Saliba e Blanco (2003), no qual, entre 100 profissionais entrevistadas, $44 \%$ afirmaram que o salário recebido pelo trabalho na odontologia não era compatível com suas necessidades básicas; e a maioria (87\%) disse não ser essa a principal fonte de renda da sua família, sendo a baixa remuneração uma das principais queixas sobre a profissão.

Entretanto, cabe ainda reafirmar a natureza contraditória da nova organização do trabalho flexível que, de um lado, exige trabalhadores qualificados, polivalentes e envolvidos física e intelectualmente, e, de outro, promove condições laborais precárias e mal remuneradas. Nessa perspectiva, Kuenze (2004) argumenta que para trabalhar em equipe e ser polivalente o trabalhador precisa, de fato, ser melhor qualificado, porém os trabalhadores não têm seus salários aumentados na medida dessa exigência. A propósito, Boltanski e Chiapelo afirmam que outro modo de "aumentar a intensidade do trabalho, menos visível que a aceleração do ritmo, é o desenvolvimento da polivalência com salário igual" (2009, p. 277).

Quando indagados sobre a existência ou não de um plano de cargos, carreira e salário - como se sabe, antiga reivindicação dos trabalhadores 
vinculados ao SUS -, todos os dentistas negaram sua existência. Decorridas mais de duas décadas desde a criação do Sistema Único de Saúde, ainda hoje não está assegurado um plano destinado a seus servidores. Esse dado aponta no sentido da não priorização para uma política de ascensão na carreira profissional, o que termina desestimulando os profissionais aos quais é atribuída a prestação de serviços.

O pressuposto de que a condição de precarização compromete a intencionalidade declarada da PNSB, como referido anteriormente, pode ser constatado nos relatos dos informantes, quando mencionaram possuir de dois até cinco vínculos empregatícios, condição essa sabidamente associada a baixos salários e ao não cumprimento da carga horária contratada.

Ao serem indagados sobre o cumprimento da jornada de trabalho, todos afirmaram não se submeterem às vinte horas semanais estabelecidas, e mais da metade mencionou cumprir apenas oito horas semanais. Os profissionais estão preocupados com essa questão, como sugerido pela fala que segue.

Muita gente acha que isso aqui é emprego, que não precisa trabalhar. Só que a população está cada vez mais exigente, ela está querendo, ela está exigindo o atendimento. Então eu acho realmente que tem que mudar... Isso só denigre a imagem da profissão, de gente que só vem enrolando, enroscada (Entrevistado J).

Nesse sentido, vale lembrar os resultados da pesquisa "Demografia médica no Brasil" (2011) que demonstram ser a condição de múltiplos vínculos incompatível com o cumprimento da carga horária contratada. Considerando que as ações regulatórias do setor privado são rigorosas, nessa condição resta o prejuízo para o(s) vínculo(s) com o setor público. Já os profissionais atribuem o seu descompromisso em razão, principalmente, das baixas remunerações.

Eu acho que realmente a gente deveria dar as quatro horas por dia, ter condições de trabalho e ter um salário condizente com a minha especialidade... Mas, a gente não é pago para isso, sabe? Então, é muito difícil, é muito difícil você ter seriedade, ter compromisso [...] (Entrevistado K).

A questão salarial influencia porque a gente tem que sair daqui para ganhar dinheiro em outro lugar. Então, não tem condições de [...] dedicar muito tempo num lugar quando não temos condições de sobreviver... (Entrevistado J).

A relação entre a disponibilidade de postos de trabalho e o valor pago pelo trabalho exercido é uma questão central nos estudos marxistas. Na sociedade capitalista, a força de trabalho, submetida às leis de mercado, obe- 
dece sempre ao fenômeno da oferta e da procura. Marx, repetidas vezes, explicou que o exército industrial de reserva é próprio e funcional ao sistema sociometabólico do capital, afinal, ele amplia a mais-valia ao regular os salários.

[...] a acumulação capitalista sempre produz, e na proporção da sua energia e de sua extensão, uma população trabalhadora supérflua relativamente, isto é, que ultrapassa as necessidades médias da expansão do capital, tornando-se, desse modo, excedente (Marx, 2011, p. 733).

Essa população excedente proporciona material humano sempre pronto para ser usado no sistema com função reguladora. Castelo Branco acrescenta que apesar da organização coletiva dos trabalhadores atuar no sentido de aumentar os seus ganhos, não se deve esquecer que outros fatores objetivos, tais como "o progresso técnico, a proletarização da população em geral, a concorrência econômica entre trabalhadores empregados e aqueles alistados involuntariamente no exército de reserva" (2006, p. 162), concorrem para que o salário médio diminua.

Penetrando o discurso dos entrevistados, não se percebe referência aos vários processos que respondem pelas mudanças no mundo do trabalho e a consequente condição de precarização. Eles interpretam o fenômeno exclusivamente pela ótica do mercado, pela dinâmica da oferta e da procura, quando diante da excessiva mão de obra ocorreria a 'desvalorização' do profissional.

A odontologia teve uma desvalorização muito grande, pelas mudanças na economia, pelo número de escolas formadoras. Consequentemente, isso é uma questão de mercado, se existem mais profissionais no mercado, logicamente a remuneração vai diminuir, vai cair (Entrevistado A).

Eu enxergo hoje o mercado de trabalho muito mais restrito porque a concorrência aumentou em função da abertura de mais escolas de Odontologia. São mais profissionais lançados no mercado anualmente, consequentemente a oferta [de postos de trabalho] ficou pequena em relação à demanda... (Entrevistado I).

Porém, a problemática das mudanças no universo laboral não se restringe apenas a aspectos do mercado. Nessa pesquisa, buscou-se compreender o cerne do problema, contextualizando-se o processo histórico que o originou, qual seja, a crise estrutural do capital e a alternativa de viés neoliberal de superação dessa crise pela via da reestruturação produtiva. Assim, as explicações dadas pelos entrevistados respondem apenas em parte à drástica redução do custo-trabalho, estando longe de associar a precarização às suas verdadeiras causas. 
A propósito, Antunes e Pochmann (2007, p. 204) argumentam que os governos nacionais ajustaram-se à fase da acumulação flexível, na medida em que passaram a adaptar a legislação social dos respectivos países às exigências do sistema global do capital e aos imperativos do mercado, destruindo profundamente os direitos do trabalho. Por causa disso é que a le-gislação social do trabalho está sendo desmontada, em cenários nos quais as resistências não demonstram força suficiente para impedir seu facelamento.

Percebe-se nos discursos dos trabalhadores que a insegurança e a instabilidade são sentimentos emergentes diante da situação atual do mundo do trabalho:

Hoje o mercado absorve de forma instável... Antes, você fazia concurso e conseguia ter estabilidade no emprego. Hoje é mais seleção simplificada e você não tem aquele vínculo de... você não tem aquela garantia de permanência no emprego... (Entrevistado F).

Dá uma insegurança... Você não sabe até quando você vai ficar. Porque o contrato acaba e a gente não sabe por quanto tempo vai ser renovado. E isso causa insegurança, mas... (Entrevistado C).

Os resultados desta investigação são parte da explicação de por que o fenômeno da precarização se faz presente nos serviços municipais de saúde bucal da Região Metropolitana do Recife, como de resto em várias outras regiões do país, e está se constituindo enquanto um problema social relevante, tendo em vista a nítida opção dos municípios em contratar a força de trabalho temporariamente, sob o amparo legal da Constituição Federal.

Ainda que fenômenos conhecidos, como o quantitativo disponível de cirurgiões-dentistas e de postos de trabalho ofertados, a adesão desses profissionais às jornadas laborais previstas nos contratos, os conflitos inerentes aos setores público e privado da atenção odontológica e a conformação do mercado de trabalho decorrente da política econômica do país possam guardar relações com a condição da precarização, o fato é que os dados arrolados nesta pesquisa chamam atenção particular para sua existência nos CEOs, existência essa legalmente amparada e justificada.

Os problemas descritos neste trabalho, tal como se apresentam, ao mesmo tempo em que impulsionam para o descompromisso com a política, revelam um conjunto de elementos comprometedores da qualidade dos cuidados prestados tendo em vista as finalidades da PNSB, cujas premissas básicas são o acesso universal, a gestão participativa, a ética, o acolhimento e a responsabilidade profissional. E não seria exagero advertir que mantida a tendência de absorção da força de trabalho mediante modalidades contratuais flexíveis essas premissas estarão em risco. 


\section{Considerações finais}

A efetivação de uma política não se dá apenas pelos propósitos de seus conteúdos ou pela disponibilidade de instrumentos legais que possam assegurá-la. Sabe-se que o grau de adesão dos agentes técnicos que devem realizá-la constitui um dos pontos de partida para o seu cumprimento. Em condições de trabalho precarizado tal como a pesquisa apontou, a responsabilidade profissional pode ser facilmente afetada. Nesse contexto, o que aparece como contraditório é o discurso associado a medidas da gestão pública que atribui responsabilidades e compromissos aos trabalhadores de saúde, ao mesmo tempo em que lhes nega satisfação e estabilidade nas condições e nos ambientes de trabalho.

No mundo contemporâneo a segurança no trabalho é um requisito imprescindível à autonomia e à luta dos trabalhadores. No caso particular dos trabalhadores do SUS que todos propõem sob controle social, é quase impossível a consecução desse princípio fora da perspectiva da estabilidade de seus trabalhadores.

Os resultados desta investigação permitem afirmar que apesar de os cirurgiões-dentistas dos CEOs serem qualificados, são baixos os valores remuneratórios que recebem pelo trabalho exercido. Ademais, realizam suas atividades profissionais à mercê de planos de cargos, carreiras e salários, e quase a metade desses trabalhadores não possui estabilidade laboral. Por todas as evidências apresentadas, é possível reafirmar que os modos instituídos de organizar a prestação de serviço na atenção à saúde bucal representam riscos para o cumprimento das prescrições dessa política.

\section{Colaboradores}

Heloisa Maria Mendonça de Morais realizou o delineamento do objeto de estudo, contribuiu na análise dos dados e discussão dos resultados e fez a revisão crítica do artigo. Raquel Santos de Oliveira coletou os dados, redigiu o artigo e participou da revisão crítica final. 
Resumen El artículo explora los cambios que vienen ocurriendo en la organización del trabajo en el ámbito de la Política Nacional de Salud Bucal, considerando las transformaciones ocurridas en la esfera del trabajo en escenario global de la reestructuración productiva. Eso fenómeno, inicialmente observado en la organización del trabajo industrial, viene siendo descrito también en el sector de servicios, siendo visibles algunos de sus efectos en el campo de la salud. En Brasil, desde la Reforma del Estado de 1995, fueron implantadas modalidades contractuales flexibles, lo que posibilitó la institución legal de vínculos precarios en la red de servicios de salud pública y privada. El presente estudio es descriptivo, con componentes propios de los abordajes cuantitativo y cualitativo. El estudio de campo fue realizado en los 13 Centros de Especialidades Odontológicas de la Región Metropolitana de Recife (Brasil) y objetivó investigar el fenómeno de la precarización y sus manifestaciones en la atención a la salud bucal. El material estudiado evidenció un contexto de precarización del trabajo en los servicios investigados, con repercusiones sobre la cualidad del atendimiento prestado a la populación usuaria de los centros, condición esa que constituye uno de los desafíos a ser enfrentados por la Política Nacional de Salud Bucal.

Palabras clave trabajo; precarización; mercado de trabajo; salud bucal.

\section{Notas}

I Doutora em Saúde Coletiva pela Universidade de Pernambuco, Recife, Pernambuco, Brasil. <raquelsoliveira78@yahoo.com.br>

Correspondência: Rua Caetano Ribeiro, 425, ap. 304, Casa Caiada, CEP 53130-440, Olinda, Pernambuco, Brasil.

2 Universidade Federal de Pernambuco, Departamento de Medicina Social, Recife, Pernambuco, Brasil. <heloisa.morais@uol.com.br>

3 A pesquisa recebeu auxílio da Bolsa Reuni de Assistência ao Ensino da Pró-reitoria de Pesquisa da Universidade Federal de Pernambuco, que resultou na dissertação de mestrado intitulada Precarização e intensificação do trabalho na atenção à saúde bucal: um estudo com cirurgiões-dentistas dos Centros de Especialidades Odontológicas, de Raquel Santos de Oliveira, apresentada ao Programa de Pós Graduação em Saúde Coletiva na Universidade Federal de Pernambuco em 2010. 


\section{Referências}

ALVES, Giovanni. Trabalho e reestruturação produtiva no Brasil neoliberal - Precarização do trabalho e redundância salarial. Revista Katálise, Florianópolis, v. 12, n. 2, p. 188-197, 2009.

ANTUNES, Ricardo. Os sentidos do trabalho: ensaio sobre a afirmação e a negação do trabalho. 9. ed. São Paulo: Boitempo, 2007.

ANTUNES, Ricardo. Adeus ao trabalho?: ensaio sobre as metamorfoses e a centralidade do mundo do trabalho. 13. ed. São Paulo: Cortez, 2008.

ANTUNES, Ricardo. As configurações do trabalho na sociedade capitalista. Revista Katálise, Florianópolis, v. 12, n. 2, p. 131132, 2009.

ANTUNES, Ricardo; POCHMANN, Márcio. A desconstrução do trabalho e a explosão do desemprego estrutural e da pobreza no Brasil. In: CATTANI, Antonio D.; CIMADAMORE, Alberto (Org.). Produção de pobreza e desigualdade na América Latina. Porto Alegre: Tomo Editorial/Clacso, 2007. P. 195-209,

BARALDI, Solange; DÍAZ, Monica Y. P.; MARTINS, Wagner J. Globalização e seus impactos na vunerabilidade e flexibilização das relações de trabalho em saúde. Trabalho, Educação e Saúde, Rio de Janeiro, v. 6, n. 3, p. 539-548, 2009.

BEHRING, Elaine R. Brasil em contra-reforma: desestruturação do Estado e perda de direitos. 2. ed. São Paulo: Cortez, 2008.

BOLTANSKI, Luc; CHIAPELLO, Ève. O novo espírito do capitalismo. São Paulo: Editora WMF Martins Fontes, 2009.

BOURDIER, Pierre. Contrafogos: táticas para enfrentar a invasão neoliberal. Rio de Janeiro: Editora Jorge Zahar, 1998.
MERLINO, Tatiana. Ruy Braga: condições de trabalho estão muito precárias. Caros Amigos, n. 182, p. 20-25, 2012.

BRASIL. Ministério da Saúde. Agentes institucionais e modalidades de contratação de pessoal no programa saúde da família no Brasil: relatório de pesquisa. Belo Horizonte: NESCON/FM/EPSM, 2002. 86 p.

BRASIL. Ministério da Saúde. Secretaria de Gestão do Trabalho e da Educação na Saúde. Gestão do trabalho e da regulação profissional em saúde: Agenda positiva. Brasília: Ministério da Saúde, 2004a. 77 p.

BRASIL. Ministério da Saúde. Coordenação de Saúde Bucal, Departamento de Atenção Básica, Secretaria de Atenção à Saúde, Ministério da Saúde. Diretrizes da Politica $\mathrm{Na}$ cional de Saúde Bucal. Brasília: Ministério da Saúde; 2004b. 16p.

BRASIL. Ministério da Saúde. Observatório de Recursos Humanos em Saúde no Brasil: Programa Saúde da Família: flexibilidade e precarização no trabalho. Brasília: Ministério da Saúde; 2006a. 23 p.

BRASIL. Ministério da Saúde. Observatório de Recursos Humanos em Saúde no Brasil: Recursos Humanos nos serviços públicos municipais de Saúde Bucal; Estação de Pesquisa de Sinais de Mercado/ NESCON/ FM/UFMG. Brasília: Ministério da Saúde, 2006b. 63 p.

CASTELO BRANCO, Rodrigo. A "questão social" na origem do capitalismo: pauperismo e luta operária na teoria social de Marx e Engels. 2006. 181f. Dissertação (Mestrado em Serviço Social) - Rio de Janeiro: Escola de Serviço Social, UFRJ, 2006.

CORDEIRO, Hesio. Descentralização, universalidade e equidade nas reformas da saúde. Ciência \& Saúde Coletiva, Rio de Janeiro, n. 6, v. 2, p. 319-328, 2001. 
DRUCK, Graça; THÉBAUD-MONY, Annie. Terceirização: a erosão dos direitos dos trabalhadores na França e no Brasil. In: DRUCK, Graça, Franco, TÂNIA (Org.). A perda da Razão Social do trabalho: terceirização e precarização. São Paulo: Boitempo, 2007. p 23-58.

GIRARDI, Sabato N. Flexibilização dos mercados de trabalho e escolha moral. Divulgação em saúde para debate, Rio de Janeiro, n. 14, p. 23-32, 1996.

GIRARDI, Sabato N. et al. Trabalho precário em saúde: tendências e perspectivas na Estratégia da Saúde da Família. Divulgação em Saúde para debate, Rio de Janeiro, n. 45, p. 11-23, 2010.

GRANEMANN, Sara. Fundações Estatais: projeto de estado do capital. In: BRAVO, Maria I. S. et al. (Org.). Política de saúde na atual conjuntura: modelos de gestão e agenda para a saúde. 2. ed. Rio de Janeiro: Rede Sirius/ Adufrj-Ssind, 2008. p.36-40.

HIRATA, Helena. A Precarização e a divisão internacional e sexual do trabalho. Revista Sociologias, Porto Alegre, ano 11, n. 21, p. 24-41, jan./jun, 2009.

KALLEBERG, Arne. L. O crescimento do trabalho precário: um desafio global. Revista Brasileira de Ciências Sociais, São Paulo, v. 24. n. 69, p. 21-30, fev. 2009.

KUENZE, Acácia Z. Sob a reestruturação produtiva, enfermeiros, professores e montadores de automóveis se encontram no sofrimento do trabalho. Trabalho, Educação e Saúde, Rio de Janeiro, n.2, v.1, p. 239-265, 2004.

LOURENÇO, Eloisio C. et al. A inserção de equipes de saúde bucal no Programa Saúde da Família no Estado de Minas Gerais. Ciência e Saúde Coletiva, Rio de Janeiro, n.14, p. 1367-1377, 2009. Suplemento 1.

MARCH, Cláudia. A Contra-reforma do Estado Brasileiro e seus efeitos no trabalho em saúde nos serviços públicos. Tempus: acta de saúde coletiva, Brasília, v. 5, n.1, p.175$186,2011$.

MARX, Karl. O capital: crítica da economia política. 25. ed. Rio de Janeiro: Civilização Brasileira, 2011. (Livro primeiro, volume II).

MENDONÇA, Maria H. M. et al. Desafios para gestão do trabalho a partir de experiência exitosas de expansão da Estratégia de Saúde da Família. Ciência \& Saúde Coletiva, Rio de Janeiro, n. 15, v. 5, p. 2335-2365, 2010 .

MÈSZÁROS, István. Para além do capital. São Paulo: Boitempo, 2002.

MOIMAZ, Suely A. S.; SALIBA, Nemre A.; BLANCO, Mikaela R. B. A força de trabalho feminino na odontologia, em Araçatuba SP. Journal of Applied Oral Science, Bauru, n. 11, v. 4, p. 301-305, 2003.

NOGUEIRA, Roberto P. Reforma do Estado, o SUS em reforma e os recursos humanos: In: SANTANA, José P.; CASTRO Jadete L. (Org.). Capacitação em desenvolvimento de recursos humanos em saúde - CADRHU. Natal: UDUFRN, 1999. p. 111-122.

NOGUEIRA, Roberto P.; BARALDI, Solange; RODRIGUES, Valdemar A. Bases normativas e conceituais da politica de desprecarização e regularização do trabalho no SUS: relatório final. Brasília: Ministério da Saúde, 2004. 78 p.

ORGANIZACIÓN INTERNACIONAL DEL TRABAJO. Trabajo decente, memoria del $\mathrm{D} i$ rector General a la $87^{a}$ reunión de la Conferencia Internacional del Trabajo. Ginebra, 1999.

RIBEIRO, Alexandre B. Vinculos de trabalho na administração Pública brasileira. Brasília: UNB, 2006. 19 p. (Observatório de recursos humanos em saúde Plano diretor 2006; NESP/CEAM/UnB).

SCHEFFER, Mario; BIANCARELLI Aureliano; CASSENOTE, Alex. Demografia 
médica no Brasil: dados gerais e descrições de desigualdades. São Paulo: Conselho Regional de Medicina do Estado de São Paulo e Conselho Federal de Medicina, 2011. 118 p.

SILVEIRA, Denise S. et al. Gestão do trabalho, da educação, da informação e comunicação na atenção básica à saúde de municípios das regiões Sul e Nordeste do Brasil. Cadernos de Saúde Pública, Rio de Janeiro, n. 26 , v. 9 , p. 1714-1726, set. 2010.
TOMASI, Elaine et al. Perfil sócio-demográfico e epidemiológico dos trabalhadores da atenção básica à saúde nas regiões Sul e Nordeste do Brasil. Cadernos de Saúde Pública, Rio de Janeiro, n. 24, S193-S201, 2008. Suplemento 1.

Recebido em 01/12/2013

Aprovado em 01/09/2014 